\title{
Direccionales con con y Marcado Diferencial de Objeto
}

\author{
Antonio Fábregas \\ Universidad de Troms $\varnothing$
}

Septiembre de 2013

\begin{abstract}
Resumen
Una propiedad del español que no ha sido estudiada con la atención que merece es la posibilidad de interpretar direccionalmente un sintagma introducido por con, como en Ven con papá, 'dirígete hacia tu padre'. Este trabajo trata de arrojar algo de luz sobre estos casos mediante un estudio de la naturaleza de los verbos que admiten la construcción, de las preposiciones involucradas en ella y de los sintagmas nominales empleados, que deben ser siempre animados (\#Ven con la silla). Este trabajo destaca la relación que se da entre estas interpretaciones direccionales y el marcado diferencial de objeto en español (MDO, como en la alternancia Vio a Ernesto frente a Vio una película). La propuesta, que sigue de cerca el análisis reciente de Rodríguez-Mondoñedo (2007) para el MDO, es que lo que subyace a la alternancia entre con y $a$ en los direccionales es que la preposición con, pero no $a$, es capaz de satisfacer un rasgo de [persona] en el SD animado.
\end{abstract}

Palabras clave: direccionales, marcado diferencial de objeto, preposiciones, animacidad, caso

\section{Interpretaciones direccionales con con}

Una de las propiedades excepcionales que tienen las construcciones con la preposición con en español es que con ciertos verbos admiten una interpretación de dirección. (1) admite dos interpretaciones: en la primera, se dice a alguien que se dirija a alguna locación no explícita en compañía de su padre. En esta interpretación, se puede sustituir la preposición por junto con o acompañado de (2).

(1) ¡Ven con papá!

(2) a. ¡Ven junto con papá!

b. ¡Ven acompañado de papá!

Pero (1) tiene una segunda lectura, que es la que nos interesa en este artículo: en ella con papá expresa el punto final del movimiento, con lo que equivale a '¡Ven hasta donde está tu padre!'; esta no admite la sustitución por junto con o acompañado de. Esta lectura con con tiene restricciones combinatorias severas que, como veremos, afectan tanto a la naturaleza del sintagma que introduce la preposición como al verbo al que acompaña. 
Esta misma construcción no está disponible en muchas otras lenguas. Ente las lenguas romance, la acepta el francés ${ }^{1}(3 \mathrm{a})$, pero la rechaza el italiano ${ }^{2}(3 \mathrm{~b})$ y el catalán ${ }^{3}(3 \mathrm{c})$. En otras lenguas, el rechazo es sistemático: el inglés (4a) la rechaza ${ }^{4}$, al igual que el ruso ${ }^{5}$ (4b), el alemán ${ }^{6}$ (4c) -donde la interpretación direccional no se obtiene ni en dativo ni en acusativo, que es directamente agramatical con mit- o el noruego $^{7}(4 \mathrm{~d})$.

$$
\begin{aligned}
& \text { a. Viens avec moi! } \\
& \text { ven.imp con mí } \\
& \text { 'iVen conmigo!' } \\
& \text { b. \#Vieni con me } \\
& \text { ven.imp con mí } \\
& \text { '¡Vayamos juntos!' } \\
& \text { c. \#Vine amb mi } \\
& \text { ven.imp con mí } \\
& \text { 'iVayamos juntos!' }
\end{aligned}
$$

(4)
a. \#Go with your mother!
ve.imp con tu madre
‘Ve acompañado por tu madre!'
b. \#poidem so mnoi
ve.imp con mí
'¡Vayamos juntos!'
c. \#Komm mit $\{$ mir $\quad / *$ mich $\}$
ven.imp con $\{$ mí.DAT / mi.AC $\}$
‘VVayamos juntos!'
d. \#Kom med meg
ven.imp con mí
‘Vayamos juntos!'

Esta construcción no se ha estudiado de forma exhaustiva en las gramáticas actuales del español, aunque ha sido observada. La NGRAE la menciona en uno de sus apartados:

[La preposición con] no tiene usos propiamente temporales, pero sí los admite locativos, ya que indica destino con algunos verbos de movimiento, como en Llevó al niño con su madre, es decir, donde estaba su madre

(Real Academia Española y Asociación de Academias de la Lengua Española, 2009,

Por su parte, De Bruyne (1999) observa la interpretación direccional en construcciones como Llevar a alguien con su madre, pero la reduce a un uso en que con significa en casa de, que no cubre todos los casos.

\footnotetext{
${ }^{1}$ Marie Laurence Knittel, comunicación personal

${ }^{2}$ Francesca Forza, comunicación personal

${ }^{3}$ Ángel Gallego y Anna Bartra, comunicación personal

${ }^{4}$ Peter Svenonius, comunicación personal

${ }^{5}$ Olga Urek, comunicación personal

${ }^{6}$ Florian Schaefer, comunicación personal

${ }^{7}$ Kristina Svensen, comunicación personal
} 
Donde significa 'concurrencia', con puede utilizarse con el significado de $\{e n / a\}$ casa de, $\{e n / a\}$ la tienda de, etc. Este valor es frecuente sobre todo en el español de América.

De Bruyne (1999, p. 664)

La interpretación direccional de (1) no implica ninguna casa, y en todo caso, esta observación no explica que en algunos casos la interpretación sea estática -de compañía o de lugar- y en otras dinámica - dirección hacia un lugar-.

La interpretación direccional es particularmente saliente en contextos imperativos, pero no se restringe a estos. Como se ve en (5), se puede obtener esta lectura en perfecto simple, imperfecto o futuro, entre otras formas, sin que parezca haber restricciones a los tiempos, aspectos o modos en los que la interpretación direccional pueda ser accesible con un verbo como $i r$.

(5) a. Tras descubrir que su madre tenía una adicción al juego, el niño fue con su padre.

b. Cuando una mujer se peleaba con su marido, volvía con sus padres.

c. Si descubrimos que en esta escuela se producen malos tratos, el chico irá con su padre.

Son varios los verbos que admiten esta lectura direccional con con. Una primera división relevante es la clásica que diferencia a los verbos de dirección inherente de los de manera de movimiento (Talmy, 1983, 1985, 1991; Morimoto, 2001; Mateu, 2002). Con los primeros, la interpretación direccional está disponible (6), mientras que con los segundos no sucede así (7) y la única lectura disponible es comitativa. Esta propiedad no es en principio sorprendente, en la medida en que los verbos de manera de movimiento tienen por lo general muy restringidas sus posibilidades de combinación con metas (8), pero sí resulta extraña si notamos que muchos de los verbos que en (7) rechazan la lectura direccional de con admiten la lectura direccional con otras preposiciones (9).
a. ¡Ven con papá!
b. ¡Ve con papá!
c. ¡Sube con papá!
d. ¡Baja con papá!
e. ¡Vuelve con papá!
a. \#¡Corre con papá!
b. \#iVuela con tu padre!
c. \#¡Nada con papá!
*Bailó a la pared.
a. Corre a tu casa.
b. Vuela a tu nido.
c. Nada a la orilla.

Sin embargo, no todos los verbos que se han clasificado como inherentemente direccionales admiten la lectura direccional de con. Con los de (10), la lectura única que se obtiene es la comitativa. Aunque un padre esté esperando a su hijo dentro de un coche, no se puede emitir (10a) para pedirle que entre y se reúna con él, por ejemplo. 

a. \#iEntra con papá!
b. \#iSal con papá!
c. \#¡Llega con papá!
d. \#iCae con papá!
e. \#iDirígete con papá!

Intuitivamente, como veremos más adelante, la diferencia entre el grupo de (6) y el de (10) es que cabe pensar que en el segundo grupo el verbo dice algo sobre la meta del movimiento, mientras que los verbos del primer grupo se limitan a indicar cierta dirección que toma el movimiento, sin imponer la naturaleza del lugar al que se llega. Dicho de otro modo: subir nos dice algo de la dirección que toma un objeto al moverse y es, en sentido propio, direccional, mientras que entrar nos dice algo sobre el lugar al que se llega -que debe estar en el interior de algo- pero nada sobre la dirección por la que se ha entrado - uno puede venir desde arriba, desde abajo, desde los lados, etc.-

Pero incluso restringiéndonos a la clase, ya de por sí limitada, de los verbos direccionales que no especifican la naturaleza de la meta del movimiento, hay más restricciones. Muchos de estos verbos admiten el clítico se, en una versión que ha sido analizada en numerosos trabajos (De Miguel, 1992; De Miguel y Fernández-Lagunilla, 2000) como un elemento que focaliza el estado resultante de los verbos. En esa versión, rechazan la lectura direccional (11).

$$
\begin{aligned}
& \text { a. \#iVente con papá! } \\
& \text { b. \#iVete con papá! } \\
& \text { c. \#iSúbete con papá! }
\end{aligned}
$$

\subsection{Su relación con el Marcado Diferencial de Objeto}

El estudio de estas construcciones es aún más intrigante cuando observamos que muestra un comportamiento semejante al que se da con el Marcado Diferencial de Objeto (de ahora en adelante, MDO) en español. Como es bien sabido (Bossong, 1985; Torrego, 1998; Delbecque, 1998; Leonetti, 2004; Rodríguez-Mondoñedo, 2007; Von Heusinger y Kaiser, 2011; López, 2012), este fenómeno se refiere a la situación en que constituyentes que desempeñan una misma función sintáctica reciben distintos tipos de marcado en función de propiedades internas de su sintagma determinante o del tipo de verbo con el que se combinan. (12) es un ejemplo prototípico de marcado diferencial aplicado al complemento directo español.

$$
\begin{aligned}
& \text { a. Vi una película. } \\
& \text { b. Vi a un amigo. }
\end{aligned}
$$

Pues bien: la posibilidad de obtener lecturas direccionales con con es paralela a las condiciones fundamentales que fuerzan la aparición de $a$ ante un complemento directo en español. Es bien sabido, por ejemplo, que la animacidad desempeña algún papel, ya que, como sucede en (12), con la mayoría de los verbos un complemento directo no animado rechaza la $a$. Lo mismo sucede con nuestra interpretación direccional: solo es posible si con introduce un sintagma nominal animado.

$$
\text { a. \#iVen con la tarima! }
$$


b. ¡Ven con tu abuela!

a. \#iVe con el árbol!

b. ¡Ve con tu abuela!

En estos dos pares se comprueba que, con sintagmas no animados, la única lectura posible es la comitativa: se pide a alguien que, al venir, traiga con él la tarima o el árbol, pero nunca que se desplace hasta la tarima o hasta el árbol.

El paralelismo es aún más estrecho. También se sabe que, aunque el MDO suele acompañar a los complementos animados, no todos los complementos animados lo admiten y hay restricciones relacionadas con la referencialidad y la especificidad (Leonetti, 2004; Von Heusinger y Kaiser, 2011). Por ejemplo, un plural escueto nunca lleva MDO aunque se refiera a personas (15).

(15) *Vi a amigos.

Lo mismo sucede en nuestro caso: la interpretación direccional se bloquea si el sintagma nominal es escueto.
a. \#iVen con profesores!
b. \#iVe con maestros!

Para el MDO clásico en español, la especificidad -aunque definida de distintas manerasfuerza la presencia de $a$, pero la no especificidad no es incompatible con la presencia de a. De hecho, es conocido que hay al menos dos pronombres personales necesariamente inespecíficos que fuerzan a: alguien y nadie.

$$
\begin{aligned}
& \text { a. } \quad \text { No vi } *(\text { a) nadie. } \\
& \text { b. } \quad \mathrm{Vi} *(\text { a }) \text { alguien. }
\end{aligned}
$$

De manera semejante, aunque sean inespecíficos, nuestra construcción admite la lectura direccional con estos elementos. Imaginemos que tenemos un juego en el que un grupo de personas se pone en círculo alrededor de otra, que tiene los ojos vendados. El objetivo es que el jugador que está en el centro vaya hacia cualquiera de las personas del círculo, y lo agarre. En este contexto, podemos emitir (18a) para darle instrucciones al jugador que está en el centro. Si el objetivo es el contrario, que el jugador del centro no llegue a tocar a ninguno de quienes lo rodean, podemos decir (18b).

$$
\begin{aligned}
& \text { a. ¡Ve con alguien! } \\
& \text { b. ¡No vayas con nadie! }
\end{aligned}
$$

Del mismo modo que otros sintagmas nominales inespecíficos admiten la $a(19)$, un inespecífico puede recibir lectura de dirección (20).

(19) Busco a una persona que sepa esto.

(20) ¡Ve con una persona que sepa esto!

El paralelismo con el MDO es más fuerte cuando reparamos en que el marcado de la interpretación direccional mediante con está casi en distribución complementaria con $a$. De la misma manera que hemos visto que los no animados no admiten la lectura direccional 
con con, parece que intentar marcar un direccional animado mediante $a$ con estos verbos da resultados marcados $(21)$.

$$
\begin{aligned}
& \text { a. *iVen a papá! } \\
& \text { b. *iVe a tu madre! }
\end{aligned}
$$

Algunos hablantes rechazan (21). Para otros, es marcada y pertenecería a un estilo de lengua literaria -bíblica, según nos dice uno de ellos-. Parece cierto, en cualquier caso, que cuando a precede a un constituyente de persona con estos verbos, en la medida en que es aceptable por los hablantes, se obtienen interpretaciones que no son prototípicamente direccionales y parecen entrar más en el territorio de la finalidad o los efectos intencionales. Este es el caso de la construcción de (22), característica de la lengua coloquial de los niños en España.

\section{¡A la seño que vas!}

Esto no indica, literalmente, que la persona a la que se dirige esta frase tenga que desplazarse físicamente hasta la profesora, sino que se el hablante planea informar a la profesora de su comportamiento. La profesora es, pues, la meta de cierta intención, por la que se espera que esta tome algún tipo de medidas contra el compañero. Dejando a un lado estos casos que no son propiamente direccionales, y que implican cierta acción prospectiva implícita, con lo que nos encontramos es con que hay un marcado diferencial de los direccionales locativos con estos verbos: a cuando son no animados y con cuando son animados.

$$
\begin{aligned}
& \text { a. ¡Ven a la tarima! } \\
& \text { b. ¡Ven con papá! }
\end{aligned}
$$

Desde esta perspectiva, el paralelismo con los casos clásicos de MDO es claro. El paralelismo, sin embargo, se refuerza cuando observamos una restricción conceptual de la construcción. Varias teorías, antiguas y modernas (Diez, 1844; Brauns, 1909; Hills, 1920; Joly, 1971; Torrego, 1998) han observado cierta correlación entre el MDO y una interpretación en que el sujeto controla la acción o podría controlarla, como en el siguiente ejemplo (Torrego, 1998, 15):

(24) a. Ernesto reclamaba a un médico.

b. *La situación reclamaba a un médico.

De la misma manera, parece que la interpretación direccional de con es posible cuando el sujeto desplazado es animado (25a) o al menos produce el desplazamiento gracias a sus propiedades internas -como en (25b), donde la naturaleza del boomerang le permite girar sobre sí mismo una vez que es lanzado, y no es necesario que intervenga otra causa para explicar el cambio de dirección tomada-.

(25) a. Ernesto volvió con su madre.

b. El boomerang volvió conmigo.

c. \#La carta volvió conmigo.

d. La carta volvió al lugar del que la habían mandado. 


\section{2. ¿Qué propiedades verbales lo permiten?}

Pasemos, en primer lugar, a explorar las propiedades que tienen en común los verbos que admiten la interpretación direccional. Ya hemos visto que hay una clase completa de verbos que no lo admiten, los verbos de manera de movimiento (26). Esto incluye a los verbos que, como se discute en Morimoto (2001) y Fábregas (2007), designan una manera de desplazamiento a lo largo de una trayectoria (27).

(26) a. \#Baila conmigo.

b. \#Tiembla conmigo.

c. \#Vibra conmigo.

(27) a. \#Corre conmigo.

b. \#Vuela conmigo.

c. \#Salta conmigo.

d. \#Cojea conmigo.

e. \#Nada conmigo.

Los verbos que admiten la interpretación direccional de con pertenecen todos a la clase de los verbos de dirección inherente, pero aquí también hay que hacer dos grupos diferentes. Los verbos de (28) la admiten, pero los verbos de (29) solo tienen una interpretación comitativa de la preposición.

(28) a. Ve con él.

b. Ven conmigo.

c. Sube conmigo.

d. Baja conmigo.

e. Vuelve conmigo.

(29) a. \#Entra conmigo.

b. \#Sal conmigo.

c. \#Llega conmigo.

d. \#Cae conmigo.

Tal vez haga falta algo más de contexto para comprobar que (28c) y (28d) pueden interpretarse direccionalmente. Para (28c) supongamos una situación en que el hablante está subido en el tejado y le pide a alguien que se reúna con él; en (28d) supongamos que el hablante está cavando una zanja y le pide a alguien que baje a reunirse con él dentro de ella. De manera interesante, este contexto no salva Entra conmigo o Cae conmigo, que siguen sin tener lectura direccional en ese contexto. Para averiguar qué sucede con estos verbos, vamos a revisar qué otras propiedades comparten los miembros de cada grupo.

\subsection{Combinación con en}

Una primera propiedad es que los verbos que admiten la lectura direccional sistemáticamente rechazan un complemento introducido por en con lectura de meta.
a. *Fue en mi casa.
b. *Vino en mi casa.
c. *Sube en el tejado. 

d. *Baja en la zanja.
e. *Vuelve en tu casa.

Nótese que subir admite algunos sintagmas con en, pero siempre que se restrinjan léxicamente a sustantivos que designan vehículos -y además, vehículos cerrados-, y con la implicatura fuerte de que la persona se monta en esos vehículos para desplazarse a otro lugar.

(31) a. Subió en el coche.

b. Subió en el avión.

c. Subió en el barco.

d. *Subió en la bicicleta.

Una propiedad importante, que nos lleva a descartar estos casos y establecer la generalización que encabeza esta subsección, es que en los ejemplos anteriores subir no tiene lectura direccional. No hay entrañamiento alguno de que la persona se desplace de abajo arriba para entrar en el vehículo. Uno puede subir en el barco bajando desde el muelle hasta la embarcación por una escalerilla. Si bien sería interesante averiguar por qué el verbo subir admite este valor, semejante a abordar, dejamos esto al margen de este trabajo, y nos concentramos en la generalización de que cuando expresa dirección no admite en.

Algunos de los verbos que rechazan con en lectura direccional también rechazan en en lectura de meta (32), mientras que otros lo aceptan (33).

(32) a. *Salió en la calle.

b. *Llegó en mi casa.

(33) a. Entró en mi casa.

b. Cayó en el suelo.

Podemos, pues, hacer una primera generalización no bicondicional:

(34) Los verbos que aceptan la lectura direccional de con rechazan la lectura de meta de $e n$.

\subsection{Combinación con hacia}

Los verbos que aceptan la lectura direccional de con aceptan también un sintagma con hacia que indica la dirección del movimiento; los verbos que rechazan la lectura relevante también rechazan hacia.

(35) a. Fue hacia mi casa.

b. Vino hacia mi casa.

c. Subió hacia la cima.

d. Bajó hacia el pueblo (desde lo alto de la montaña)

e. Volvió hacia mí.

(36) a. *Entró hacia la cocina.

b. *Salió hacia la calle.

c. *Llegó hacia mi casa.

d. *Cayó hacia las piedras. 
La preposición hacia da lecturas direccionales, pero nunca implica la meta del movimiento. Su distribución es casi complementaria - salvo para los verbos llegar y salir-con la disponibilidad de una lectura de meta con en. Hacemos, pues, la segunda generalización, esta sí bidireccional.

(37) Un verbo admite la lectura direccional de con si y solo si admite también modificadores direccionales con hacia

La preposición hacia se limita a dar una dirección, y es tan claro que no implica que se alcance una meta que ni siquiera requiere un desplazamiento físico a través de una trayectoria, como muestran los ejemplos de orientación de (38).

(38) a. Pon la cama hacia la ventana. ('Pon la cama mirando hacia la ventana')

b. *Pon la cama a la ventana. (\#'Pon la cama mirando hacia la ventana')

Hay aparentes contraejemplos con salir, que a veces admite hacia.

(39) Salió hacia Barcelona.

La razón de que estos ejemplos no contradigan la generalización anterior es que no describen la trayectoria que se lexicaliza mediante salir. Dicho de otro modo, la dirección que se muestra con hacia Barcelona no es necesariamente la que tiene el movimiento de dentro afuera que caracteriza a este verbo. En un sentido intuitivo, cuando uno sale de viaje desde su casa en dirección a Barcelona, la salida de su casa no tiene por qué ir ya en dirección hacia Barcelona. Como prueba algo más formal, véase que con el verbo salir la presencia de hacia no bloquea que se introduzcan otros modificadores que indiquen movimientos de dentro afuera, marcando tanto el punto de partida como la meta descrita por salir.

(40) a. Salió para el aeropuerto hacia Barcelona.

b. ??Salió de su casa a la calle hacia Barcelona.

En cambio, con los verbos que admiten la lectura direccional de con, hacia bloquea que se introduzcan otras metas, porque hacia propiamente designa la dirección del desplazamiento designado por el verbo. En el primer ejemplo, podríamos pensar que alguien quiere llegar a una tienda que está alineada con mi casa, de manera que un desplazamiento por esa trayectoria tenga dirección hacia mi casa, pero la oración sigue siendo agramatical.

(41) a. *Fue a la tienda hacia mi casa.

b. *Bajó para la tienda hacia la ladera del monte.

c. *Fue desde Madrid hasta Albacete hacia Alicante.

\subsection{Propuesta}

A la luz de los datos anteriores, proponemos que la generalización es la siguiente:

(42) Un verbo admite la lectura direccional con con cuando implica una dirección pero no la meta del movimiento. 
Esta generalización elimina automáticamente todos los verbos de manera de movimiento, con o sin trayectoria, como posibles candidatos a tener lecturas direccionales con con: ninguno de ellos dice nada sobre la dirección que debe seguir la trayectoria, si es que esta existe -uno puede volar hacia arriba, hacia abajo, hacia adentro, hacia los lados, etc.-

En cuanto a los verbos que se han llamado direccionales, los separa en dos clases. Los verbos ir, venir, bajar, subir y volver designan distintas propiedades de las direcciones que toman los objetos en movimiento. Estas propiedades pueden clasificarse en dos clases:

1. El sentido de la dirección: si es hacia un punto de referencia o desde un punto de referencia

2. La orientación de la dirección: si es hacia arriba o hacia abajo

La primera división distingue ir de venir, siguiendo la distinción deíctica tradicional acerca de si el final del movimiento está en contacto con un hablante o se aleja de él. En cuanto a volver, es como ir pero con la presuposición de que el objeto que se desplaza ya había ocupado la posición meta anteriormente. La segunda división diferencia subir de bajar.

El hecho de que estos verbos simplemente designen propiedades de las direcciones, sin tener que decir nada sobre la meta que se alcanza, explica que acepten hacia, que no implica que se alcance una meta pero sí que haya cierta dirección. De igual manera explica que rechacen en en lectura de meta, porque esa lectura solo puede obtenerse con una preposición como en cuando el verbo tiene algo que decir sobre el estado resultante que se alcanza tras un proceso de cambio o de desplazamiento.

(43) a. Rompió el jarrón en mil pedazos (hizo un cambio que concluyó con el estado en que el jarrón está en mil pedazos)

b. Recogió las hojas en un montón (hizo un cambio que concluyó con el estado en que las hojas están en un montón)

c. Entró en la habitación (hubo un movimiento que concluyó con el estado en que él está en la habitación)

Los otros verbos, que rechazan con en la lectura direccional son esencialmente verbos que dicen algo de la locación que se alcanza, pero no necesariamente sobre la dirección que se sigue. Si estos verbos designan algo sobre la locación alcanzada, pero no sobre la dirección, esperamos que se dé la distribución de sintagmas preposicionales que hemos notado: sistemáticamente rechazan la preposición direccional hacia, porque esta preposición es direccional y los verbos carecen propiamente de un componente direccional. Admiten, con alguna excepción explicable independientemente, los sintagmas de meta con en, porque pueden legitimar una meta, que es parte necesaria de su componente interno.

Lo que queremos defender, antes de entrar en los detalles técnicos, puede decirse de forma aún más clara: entrar no denota una dirección hacia adentro, sino alcanzar una meta que está en el interior de algo; salir indica alcanzar un lugar exterior; llegar es alcanzar un punto elegido arbitrariamente y caer es llegar a un lugar situado en posición inferior. Dicho de otra forma, estamos proponiendo que -pese a las intuiciones inicialescaer no designa una dirección hacia abajo, sino que indica que se alcanza una locación que se encuentra necesariamente más abajo que la posición inicial del objeto desplazado. En nuestro conocimiento del mundo, no está claro que estas dos situaciones sean diferentes -la 
de indicar una dirección hacia abajo y la de indicar que se alcanza una posición más baja, pero hay algún fenómeno que apunta en esta dirección. Concretamente, consideremos el contraste de (44). Imaginemos que estamos en una habitación en cuyo techo hay una trampilla que lleva a una buhardilla. Supongamos que justo bajo esa trampilla ponemos una mesa para ayudar a alguien a encaramarse a la buhardilla. Cuando la persona que estaba en la buhardilla baja o cae por la trampilla para regresar a la habitación, la primera oración es imposible, pero no la segunda.
a. Cayó sobre la mesa.
b. *Bajó sobre la mesa.

¿A qué se debe este contraste? Lo que queremos defender es que se sigue naturalmente si bajar indica una dirección, pero caer indica una meta. Siguiendo a Svenonius (2010) asumimos que una preposición locativa como sobre es proyectiva, es decir, define cierta área proyectando vectores abstractos en cierta dirección con respecto a un objeto. En un sintagma como sobre la mesa, lo que hace sobre es, a partir del área definida como la mesa, proyectar vectores hacia arriba, y eso define el área relevante. Concretamente, la existencia de estos vectores puede probarse porque es posible medir su extensión gramaticalmente:

Estaba dos metros sobre el nivel del mar.

Aquí estamos acotando el área relevante de sobre a los vectores que tienen la extensión de dos metros. Svenonius muestra también que los vectores pueden tener cierta orientación, un asunto que dejaremos de lado.

Si esto es así, tenemos una explicación de por qué (44a) es agramatical. Lo que sucede es, sencillamente, que los vectores que proyecta sobre tienen una dirección determinada, que parte de la mesa y va hacia arriba. El verbo bajar también tiene una dirección, pero esta es de sentido opuesto: hacia abajo. El choque entre estas dos direcciones produce agramaticalidad, y como consecuencia la oración no es aceptable.

En cambio, este problema no surge con Cayó sobre la mesa, que es completamente aceptable. La razón es que caer no especifica gramaticalmente la dirección: sencillamente, indica que se alcanza una locación inferior, y de aquí podemos seguir, por nuestro conocimiento del mundo, que para llegar a ella se debe haber seguido una dirección hacia abajo, pero nada en la denotación del verbo denota dicha dirección. Por lo tanto, no hay ninguna dirección de sentido contrario a los vectores que define sobre.

Pasemos ya a la formalización de cada clase de verbos. Por explicitud, vamos a adoptar un modelo de descomposición del significado en nudos morfosintácticos que sigue de cerca las propuestas de Hale y Keyser (2002), Mateu (2002) o Ramchand (2008), pero el análisis que defenderemos podría formalizarse igualmente mediante plantillas léxico-conceptuales (?), en cuyo caso bastaría con interpretar la estructura representada mediante un árbol como una serie de primitivos conceptuales. Hasta donde se nos alcanza, nada de nuestra contribución depende forzosamente de la elección entre estos dos marcos teóricos.

Dicho esto, proponemos que la estructura sintáctica interna de los verbos realmente direccionales es la de (46). 
$(46)$

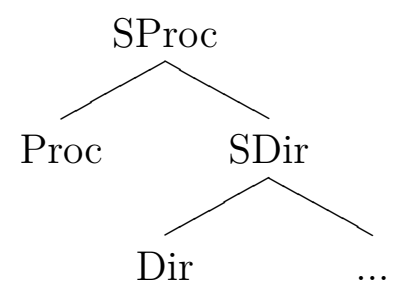

Aquí estamos siguiendo la nomenclatura de Ramchand (2008) en combinación con las proyecciones preposicionales de Svenonius (2010). El Sintagma Proceso o SProc es la proyección verbal que dota de dinamicidad a un predicado; contiene el argumento davidsoniano $e$, y en el caso de un verbo de movimiento designa el desarrollo del desplazamiento de un punto a otro. Toma como complemento un Sintagma Direccional, o SDir, que es el que dota de dirección a ese movimiento. Con esto formalizamos que verbos como ir dicen algo de cierta dirección. Suponemos que Dir puede tener distintas propiedades semánticas, referidas a las propiedades de orientación y sentido que hemos mencionado anteriormente; dejamos abierta la pregunta de si las diferentes interpretaciones deben codificarse conceptualmente -por lo tanto, no representándolas en el árbol-, mediante distintos sabores del núcleo Dir -a la manera en que Harley (1995) analiza los distintos sabores del verbo- o mediante modificadores sintácticos - en la línea de lo que propone recientemente el trabajo de Romeu (2013)-.

Dada la estructura de (46), el resto de propiedades observadas se siguen. La preposición hacia estará legitimada porque puede ser tomada como complemento de Dir - evitamos darle etiqueta a esta preposición para ser neutrales con su análisis interno, cf. Romeu (2013)-:

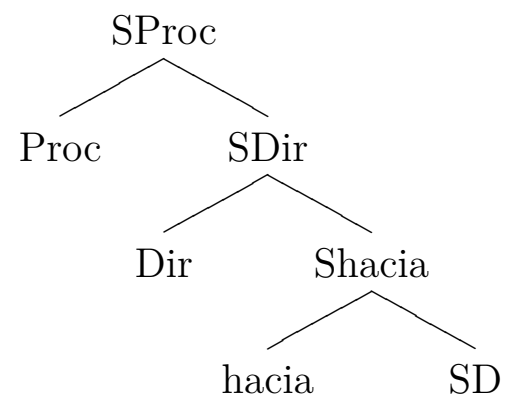

En cambio, esperamos que se rechace la lectura de meta de en, por el sencillo motivo de que esta preposición es locativa y solo puede designar metas cuando se toma como complemento de una proyección que codifica el estadio resultante. (48) es agramatical porque en no puede interpretarse como un lugar estático, ya que es complemento de un núcleo de dirección que exige desplazamiento. En cambio, en (49), la preposición está legitimada, porque es complemento de una proyección estativa que designa el estado resultante del movimiento -Ramchand (2008, 80)- por lo que su propia carencia de dinamicidad concuerda con la de la proyección que la domina. La interpretación es la de una locación resultante. 
$(48)$

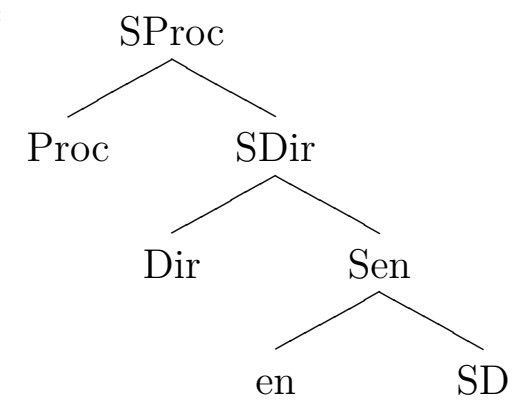

(49)

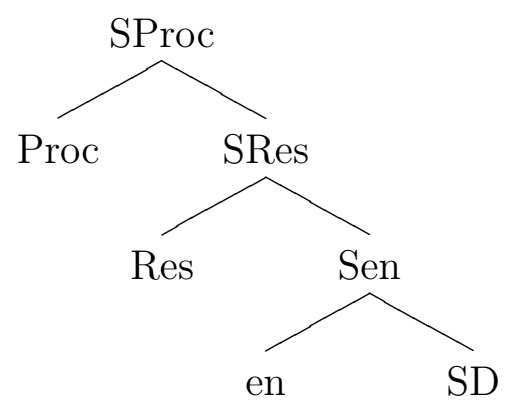

Inversamente, la estructura de los verbos de la clase de caer, que rechazan la interpretación direccional de con, es la de (50).

$(50)$

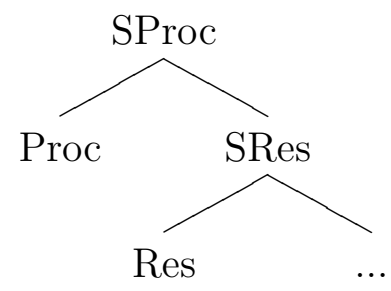

Esta estructura legitima en principio un sintagma preposicional locativo que exprese la locación resultante.

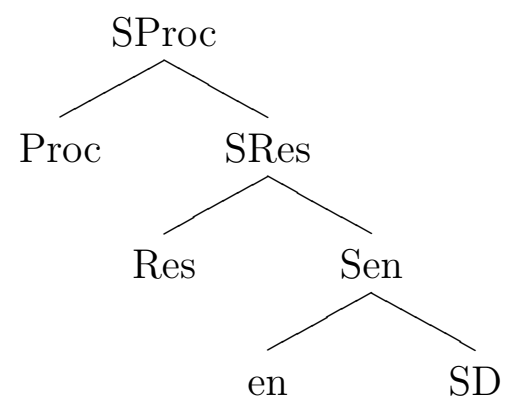

Tenemos que decir algo de los verbos de esta clase que rechazan en. Estos son verbos que rechazan en porque algún aspecto de su semántica entra en conflicto con lo que designa en. Esta preposición tiene una propiedad fundamental: indica una relación estática de inclusión dentro de un área, como se ilustra en (53), donde lo que se dice es que Ernesto está incluido dentro del área definida por la casa.

(52) Ernesto está en la casa. 
El problema de llegar es que focaliza el punto en el que el objeto desplazado entra en contacto con la meta, sin suponer una relación de inclusión total. Es decir: llegar es alcanzar el límite de la meta. Quién llega a casa, frente a quien entra a casa, puede quedarse en la puerta. Por esta razón, la locación alcanzada con este verbo no es una que pueda expresarse sin conflicto semántico con una preposición de inclusión como en. Siguiendo a Fábregas (2007) asumimos que $a$ es una preposición locativa, y siguiendo a Romeu (2013) asumimos que la relación que expresa es la de falta de coincidencia o solapamiento entre dos puntos. En la estructura de (57), la interpretación es que se alcanza una posición distinta de la que se tenía en el punto de partida, que debe ser necesariamente distinta de la que define el área de la casa, y la interpretación de falta de coincidencia de $a$ añade además que Ernesto está en el límite del área de la casa, sin decir necesariamente que entrara en ella.

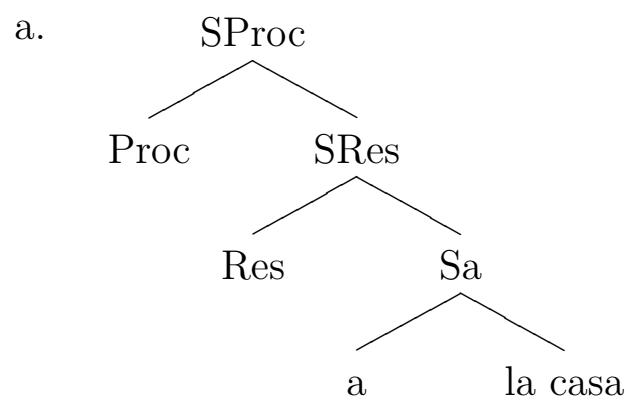

b. Ernesto llegó a la casa.

Con salir sucede algo parecido: en presupone que hay una relación de coincidencia entre un área y el viajero, pero el verbo salir focaliza el punto de partida, no el de llegada. Lo que indica salir es que hay una relación de coincidencia entre Ernesto y alguna locación cerrada que ocupa antes de iniciar el desplazamiento; la preposición $a$, con su falta de coincidencia, indica que el punto de llegada implica cruzar el límite de esa locación, indicando necesariamente que se ha dejado de estar incluido en ella y se ha alcanzado el límite de otra área.

$$
\text { Ernesto salió a la calle. }
$$

Por tanto, los casos en que los verbos que rechazan con en lectura direccional rechazan en se deben a sus implicaciones semánticas y no a la carencia de estructura suficiente para indicar metas alcanzadas.

Inversamente, estos verbos rechazan hacia porque dada su estructura, el complemento preposicional estaría introducido por SRes. Sin embargo, SRes es estático -designa una locación alcanzada y no un desplazamiento- y esto entra en conflicto con la semántica de la preposición direccional, que pide desplazamiento figurado o no a través de una trayectoria. 
$(55)$

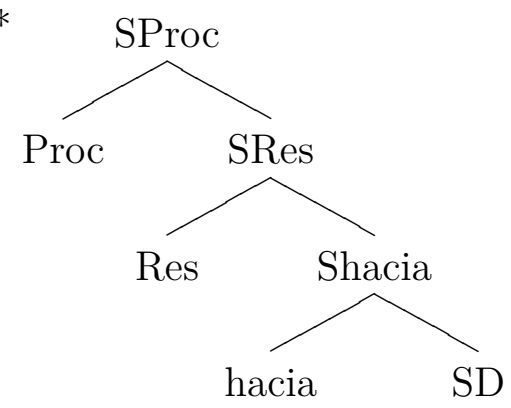

Recapitulemos brevemente lo que sabemos, aplicándolo ya al caso de los direccionales que introduce con: esta lectura solo se da con verbos que muestran independientemente poseer un sintagma direccional en su estructura interna. En cambio, cuando el nudo más bajo de estructura que introduce el verbo es un sintagma de estado resultante, la lectura es imposible. Llegados a este punto, recordemos otra de las restricciones: la interpretación direccional se bloquea si el verbo aparece con la forma pronominal se:
a. Ernesto fue con su madre [posiblemente direccional]
b. \#Ernesto se fue con su madre [nunca direccional]

La conexión entre esta restricción y la anterior se convierte en obvia si consideramos las teorías en las que se, al menos el se pronominal que acompaña a ciertos verbos, fuerza la introducción de un sintagma de resultado. Hay distintas pruebas de que esta relación es plausible. De Miguel y Fernández-Lagunilla (2000) observan que la presencia de se incluye un componente de resultado en la denotación del verbo - en otros casos, fuerza a focalizar el estado resultante-, y va asociado a alcanzar cierto cambio.

Contrastes como los de (57) muestran la diferencia con claridad: sin se, el verbo designa posiblemente una actividad continua, pero con $s e$, se fuerza la lectura en que se pasa por una transición, es decir, se alcanza el estado de estar dormido. De manera semejante, caer puede indicar la actividad continua de desplazarse hacia una meta, pero con se, denota necesariamente que se alcanza esa meta.

a. Ernesto durmió.

b. Ernesto se durmió.

a. Cuando hay deflación, los precios caen.

b. El jarrón se cayó.

Se ha observado que cuando un predicado contiene un elemento resultativo -es decir, un SRes- ese elemento resultativo puede seleccionar complementos directos y otros modificadores que, por sí solo, el verbo no puede legitimar. (59) ilustra este fenómeno para el inglés. Cuando aparece el adjetivo resultativo, es posible seleccionar un complemento directo.
a. *John laughs himself.
John ríe sí-mismo
'Ernesto ríe él mismo'
b. John laughs himself silly.
John ríe sí-mismo tonto
'Ernesto se ríe hasta quedarse tonto' 
Pues bien: De Cuyper (2004) nota que en español la presencia de se tiene un papel similar. Puede extender la selección semántica de los complementos directos, como se muestra en el contraste de (60), o incluso permitir relaciones argumentales entre sujeto y complemento que de otra manera no se darían con ese verbo (61).

(60) a. *Ernesto come las palabras.

b. Ernesto se come las palabras.

(61) a. *La mesa come la habitación.

b. La mesa se come la habituación.

Esta autora también nota que con se, un modificador verbal puede ser ambiguo: se puede interpretar como modificando al proceso en sí o al estado resultante. Sin el se, con el mismo verbo, el mismo modificador solo admite la modificación del proceso. En la primera de las dos oraciones siguientes interpretamos que María estuvo a punto de iniciar la acción de comer la sopa, pero no llegó a probarla; con la segunda, además de esta lectura, admitimos aquella en que come parte de la sopa, pero no alcanza el resultado final en que la sopa esté consumida por completo.

(62) a. María casi come la sopa (, pero descubrió a tiempo que estaba envenenada).

b. María casi se come la sopa (, pero era demasiada y no pudo terminarla).

Todos estos fenómenos se siguen si asociado a la presencia de se pronominal tenemos una operación sobre la estructura aspectual que define un SRes. Este elemento fuerza una interpretación de cambio, puede introducir sus propios argumentos y está disponible para que operadores como casi lo modifiquen, en lugar de al Proceso. Hay varias formas de representar la asociación entre SRes y se, y son ortogonales a nuestros propósitos; en el siguiente árbol lo representamos de la forma más simple compatible con los datos: se encabeza un SRes.

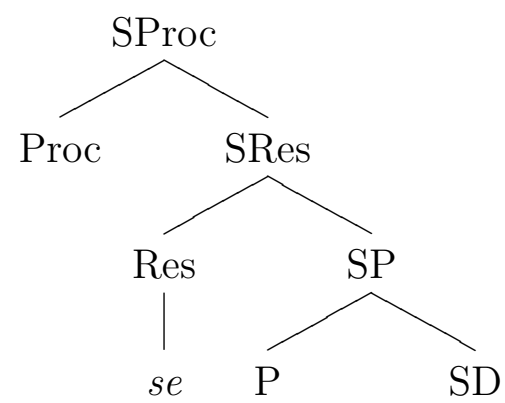

Por tanto, lo que esperamos que suceda con un verbo como ir cuando añadimos el se es que se incluya en su estructura un SRes: 
$(64)$

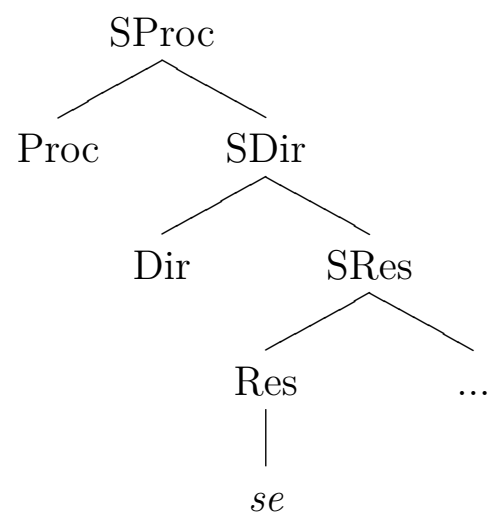

Consecuentemente, y si este análisis es correcto, esperamos que en la versión con se, estos verbos rechacen hacia, porque este sintagma debería ser introducido como complemento de SRes. Esta predicción se confirma:

(65) a. Ernesto vino hacia mí.

b. *Ernesto se vino hacia mí.

\section{Direccionalidad y con}

De lo establecido mediante las pruebas anteriores, se sigue que la estructura de ir con Ernesto, en su interpretación direccional, es la de (75).

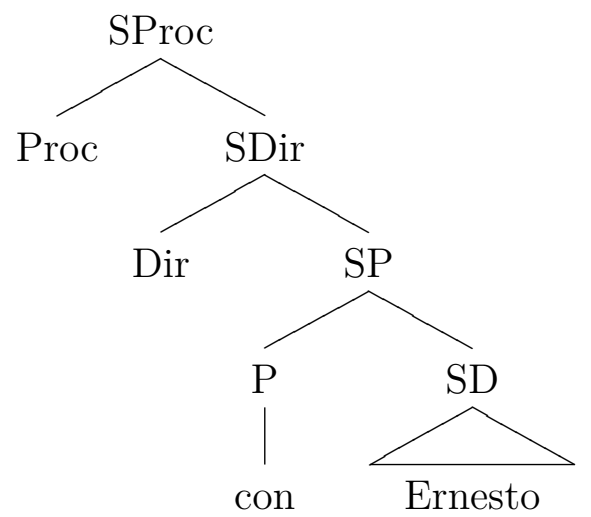

Expliquemos ahora cómo se puede obtener la semántica relevante. El verbo lexicaliza la estructura que incluye SProc -es decir, un cambio dinámico con un desarrollo, en este caso en un eje espacial- y SDir, que indica la dirección que sigue ese movimiento y permite diferenciar distintos verbos en función de su orientación y sentido. Proponemos tratar, siguiendo a Romeu (2013), estas propiedades como modificadores de un núcleo direccional. El siguiente árbol representa la estructura lexicalizada por el verbo subir. 


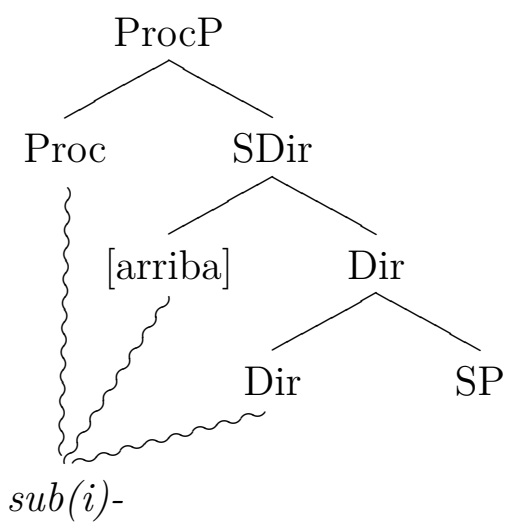

Lo que trata de representar esta estructura es que el verbo se asocia léxicamente a esos tres elementos. La formalización que adoptamos es la de Materialización de Sintagma, tal y como se defiende, entre otros, en Weerman y Evers-Vermeul (2002); Neeleman y Szendrői (2007); Fábregas (2007); Starke (2009); Caha (2009): un solo exponente morfofonológico puede materializar cumulativamente un constituyente complejo. Esta elección está motivada por razones externas a los fenómenos que se discuten aquí; la asociación podría producirse de otros modos -por ejemplo, como primitivos semánticos en el léxicoy no cambiaría nada en lo esencial dentro de nuestro análisis.

La estructura preposicional con con está introducida como complemento de Dir. Siguiendo a Hale (1986), citethalekeyser02 y Mateu (2002), asumimos la existencia de dos tipos de nudos relacionales: de coincidencia central y de coincidencia terminal. La coincidencia central establece una relación necesariamente estática en la que un objeto está completamente incluido dentro de otro, donde hay solapamiento completo de uno en el otro. Los autores antes citados relacionan esta preposición con la atelicidad, ya que una relación de coincidencia central no define límites que puedan emplearse para medir el final de un cambio. En cambio, una preposición de coincidencia terminal expresa un contacto entre dos entidades en uno de sus puntos. Esta clase de estructuras se asocian con la telicidad y el cambio, ya que el punto en el que entran en contacto puede tomarse como el límite de un proceso.

Contra lo afirmado por algunos autores -véase Rapoport (to appear) o Hale y Keyser $(2002,160)$, que tratan with como una preposición de coincidencia central- tratamos la preposición con como un elemento relacional que muestra una relación de no inclusión que, sin embargo, supone un contacto en un punto - una preposición de coincidencia terminal, al menos para el español. Esta propuesta está apoyada por varios fenómenos. Brucart $(2010,2012)$ argumenta que en las construcciones con estar, la estructura predicativa contiene una preposición de coincidencia terminal. Esto explica la asociación con una situación externa que es definitorio de las predicaciones con este verbo (Arche, 2006): con estar, los adjetivos que admiten ambos valores se interpretan como expresión de situaciones que surgen como resultado de un cambio anterior, implícito o explícito.

(68) a. La fruta está madura.

b. María está gorda.

c. Pedro está moreno.

d. Tu nariz está roja. 
Esto es esperable si las predicaciones con estar implican una relación de coincidencia terminal: el límite definido que denotan estos relatores proporciona el punto inicial del estado, que por lo tanto se puede reinterpretar como resultado de un cambio (implícito o no). Necesariamente, esta relación será de predicado de estadio, porque una propiedad que surge como resultado de alguna situación en la que se encuentra el individuo no puede ser característica, es decir, no puede ser parte de la definición de la entidad de ese individuo.

Con este trasfondo, volvamos al caso de la preposición. Cuando con se emplea como complemento de un verbo copulativo, selecciona necesariamente estar.
a. Ernesto está con María.
b. *Ernesto es con María.

Los sintagmas con con pueden emplearse para expresar relaciones de posesión, pero siempre y cuando sea posesión temporal y no definitoria del individuo.

(70) a. María está con un abrigo en esta foto.

b. Luis está con sombrero.

Si la posesión es estable temporalmente, o se refiere a partes del cuerpo y otras propiedades inalienables, con no funciona, y se debe emplear tener.

(71) a. *Ernesto está con bigote.

b. Ernesto tiene bigote.

a. *Ernesto está con un coche.

b. Ernesto tiene un coche.

Otra propiedad que sugiere que con define propiedades de estadio y, por lo tanto, es una preposición de coincidencia terminal, es que puede funcionar como complemento predicativo. $^{8}$

(73) Vino a la fiesta con sombrero.

Si con, al menos en español, es una preposición de coincidencia terminal $\left(\mathrm{P}_{t}\right)$, su integración en la estructura direccional es directa. Una vez que aparece de complemento de un núcleo que designa una dirección a lo largo del espacio, con proporciona un límite para ese movimiento, que se define por el contacto entre la entidad desplazada y la entidad a la que alcanza.

\footnotetext{
${ }^{8}$ La interpretación semántica asociada a con también suele ser de coincidencia terminal, frente a inclusión. Si decimos Ernesto con María establecemos un contacto entre ellos, pero obviamente no suponemos que uno esté en el interior de otro. Nos pueden servir un plato de espaguetis con tomate en el que el tomate no cubre por completo la pasta, sino que se encuentra en el centro; basta con que haya contacto entre los dos. Ocasionalmente, si las sustancias que se combinan pueden mezclarse, entendemos una lectura más cercana a la coincidencia central -como en café con leche-, pero esto es un efecto conceptual que se deriva de nuestro conocimiento del mundo acerca de qué entidades se disuelven en otras, lo cual no puede caracterizarse mediante rasgos formales.
} 
$(74)$

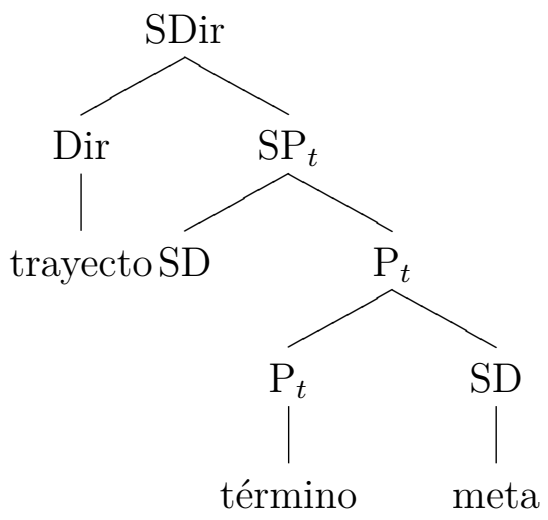

Por la misma razón, una preposición de coincidencia central $\left(\mathrm{P}_{c}\right)$-que exige una relación de inclusión sin límites definidos- como en se rechaza en construcción con estos verbos. Dir selecciona cierto tipo de preposiciones, y admite las que son como con o $a$, en la medida en que no designan relaciones de inclusión, y esta es la causa última de la agramaticalidad de ${ }^{*}$ ir en casa.

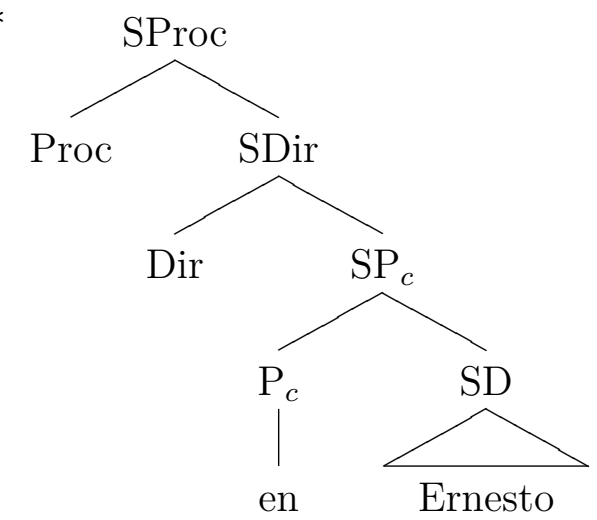

\subsection{Con y a como direccionales}

Recordemos la alternancia que se da, paralela al carácter animado o no del complemento, entre con y $a$. Los siguientes ejemplos asumen la lectura direccional, y se descarta de antemano la comitativa.

(76) a. Ve con tu hermano.

b. *Ve con la mesa.

(77) a. *Ve a tu hermano

b. Ve a la mesa.

Las dos construcciones parecen recibir la misma interpretación, de tal manera que la alternancia se debe a otros factores. La primera pregunta que surge es si ambos sintagmas aparecen en la misma posición sintáctica.

La oración de (78) sugiere que sí. Cuando concurren los sintagmas con con y $a$, no es posible interpretar ambos como direccionales -incluso si podemos establecer una relación entre los dos-. Aunque supongamos que el padre está encima de la tarima, de manera que se puede ir a la tarima y hacia el padre a la vez, o incluso llegar a la tarima y continuar 
sobre ella hasta llegar al padre, (78) no se puede emplear para decir esto. En esta oración, la única lectura posible de con es comitativa: Ernesto se dirige, acompañado de su padre, hasta la tarima.

(78) Ernesto fue con su padre a la tarima.

El orden entre los dos complementos no altera esto. Es difícil medir el alcance relativo de cada uno de los direccionales con respecto a otros elementos, porque la naturaleza de estos verbos hace que no admitan otros argumentos más allá de la entidad que se desplaza y el direccional. Sin embargo, hasta donde el alcance se puede diagnosticar, ambas construcciones funcionan igual. No se dan asimetrías en cuanto al alcance de los cuantificadores contenidos en los dos tipos de complemento direccional y el sujeto. En los dos ejemplos siguientes, el direccional tiene un cuantificador universal distributivo -caday en ambos casos es posible interpretar distributivamente el sujeto indefinido -hay varios estudiantes, cada uno va hacia un lugar-. Supongamos, para la primera oración, que hay un juego de campamento en el que tres estudiantes tienen que correr hacia un monitor distinto, de manera que gana quien llegue antes.

(79) a. Un estudiante fue con cada monitor.

b. Un estudiante fue a cada casa.

Tampoco hay asimetrías entre los dos elementos en la dirección inversa (80) o con numerales (81).

(80) a. Cada estudiante fue con un monitor.

b. Cada estudiante fue a una casa.

(81) a. Un estudiante fue con tres monitores.

b. Un estudiante fue a tres casas.

Un adjunto que presumiblemente está en el área de SProc -porque modifica la parte dinámica del evento, al dar propiedades de su velocidad-también se comporta con respecto al alcance del mismo modo con ambos direccionales. Si el juego consiste en correr a un lugar a distintas velocidades, ambas oraciones son igualmente adecuadas.

(82) a. Ernesto fue con cada monitor a una velocidad distinta.

b. Ernesto fue a cada casa a una velocidad distinta.

Igualmente, como adverbio, puede ordenarse delante o detrás del direccional sin que se pierda ningún significado en ninguno de los dos casos.

(83) a. Ernesto fue rápidamente con su padre.

b. Ernesto fue con su padre rápidamente.

(84) a. Ernesto fue rápidamente a su casa.

b. Ernesto fue a su casa rápidamente.

Las pruebas apuntan, pues, a que ambos elementos están en la misma posición. Esto nos lleva a la conclusión de que el sintagma preposicional con a es también complemento de Dir, y por tanto, a que tenemos una alternancia entre dos marcados preposicionales para la misma clase de elementos. 


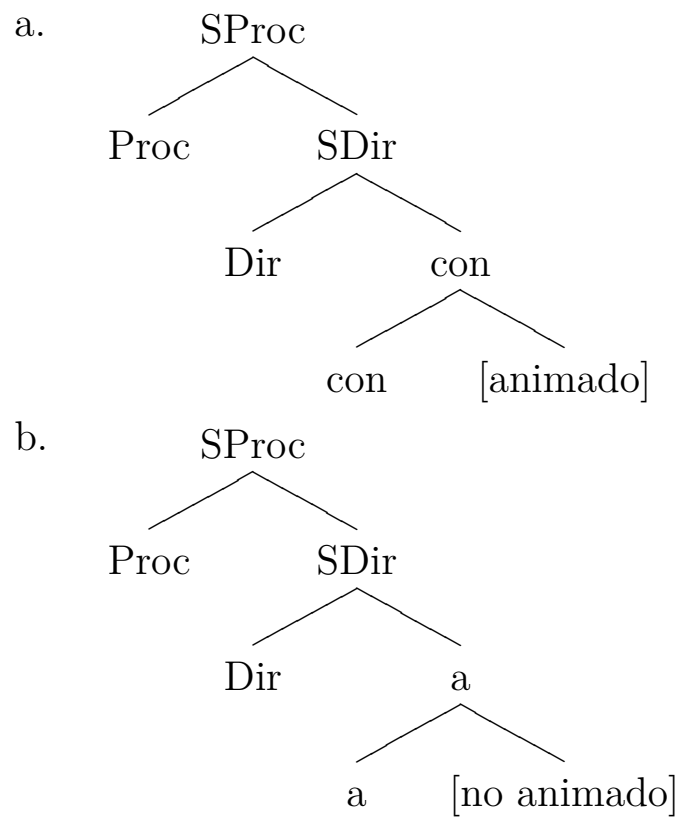

La pregunta es, naturalmente, por qué debe darse esta alternancia, y a eso dedicaremos la siguiente sección de este artículo.

\section{Direccionales con con y Marcado diferencial de ob- jeto}

En la sección 1.1 observamos datos que muestran un paralelismo inicial entre la direccionalidad con con y el marcado diferencial de objeto (MDO): solo puede darse con animados, y no es posible con nominales escuetos, aunque sí con los pronombres necesariamente inespecíficos alguien y nadie.
a. \#Vete con su maleta.
b. \#Vete con amigos.
c. Vete con alguien.

La bibliografía sobre el marcado diferencial de objeto es enorme en español, y no seremos capaces de hacer justicia a ella. Dejando al margen los trabajos de corte funcional y cognitivo (Pottier, 1968; Delbecque, 1998, 1999, 2002; Company, 2002; Enghels, 2013), y concentrándonos solo en los trabajos encuadrados dentro de la sintaxis generativa, hay tres propuestas fundamentales hechas en tiempos recientes, y que ocasionalmente se solapan en algunos de sus aspectos:

- El MDO es necesariamente el efecto de un desplazamiento a una posición distinta de la que ocupan los complementos directos ordinarios.

- El MDO es en último término el resultado de una operación morfofonológica que marca de manera especial ciertos elementos que funcionan como complemento directo. 
- El MDO es en último término el resultado de una operación de concordancia distinta a la que sufren los complementos directos no marcados.

Torrego (1998) y López (2012) son dos autores para quienes necesariamente un complemento directo con marcado diferencial debe desplazarse a una posición verbal -en la primera autora, al nudo $v$ pequeña y en el segundo, a un nudo intermedio entre $v$ pequeña y $\mathrm{V}-$, a la que es atraído por razones interpretativas. Es crucial en esta propuesta que el elemento atraído tenga naturaleza nominal, ya que el movimiento se produce en relación con la necesidad de asignar caso. En el siguiente árbol representamos la propuesta de López (2012).

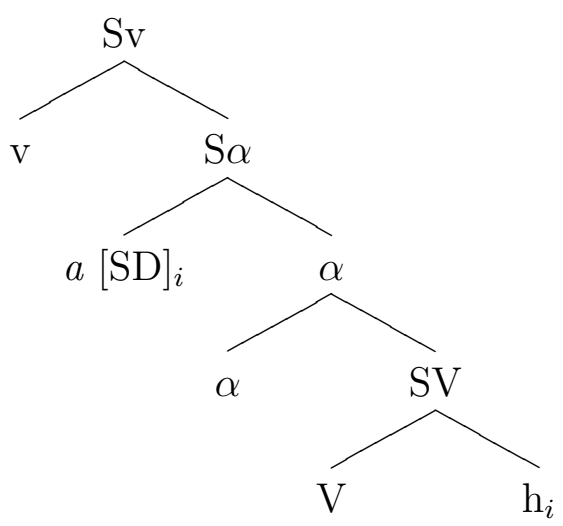

Una comparación con el caso de los direccionales introducidos por con sugiere que el desplazamiento no es la propiedad definitoria del MDO en español. Si el paralelismo entre el MDO con el complemento directo y el caso del direccional fuera completo, esperaríamos que el direccional con con se desplazara a otra posición más alta que la que ocupan los direccionales con $a$. Ya hemos visto que no parece haber asimetrías con respecto a la posición que cada uno de estos dos elementos ocupa. Esto, de hecho, puede ser esperable en la teoría de Torrego (1998) y López (2012), en la medida en que los direccionales deben estar necesariamente introducidos por una preposición. Si el desplazamiento que estos autores asocian al MDO afecta a las categorías nominales, se sigue que no podrá afectar a los sintagmas preposicionales. Con todo, lo que esta comparación nos indica es que un tratamiento unificado del MDO en español no puede dar el desplazamiento como rasgo diferencial y derivar otras propiedades a partir de allí -como sí hace Torrego (1998)-; más bien cabe pensar que el MDO debe definirse con respecto a las propiedades del elemento y derivar, a partir de esas propiedades, su desplazamiento.

En la propuesta de López (2012) la causa última de que ciertos complementos directos estén introducidos por $a$ no es estrictamente sintáctica, sino morfológica. El componente morfológico de ciertas lenguas - o variedades- contiene una serie de reglas idiosincrásicas de materialización que fuerzan al marcado de caso con $a$ en ciertos contextos. Siguiendo los postulados de la Morfología Distribuida (Halle y Marantz, 1993) y la teoría del caso como un marcado morfofonológico sensible al contexto sintáctico (Marantz, 1991), López $(2012,60)$ propone que la gramática española determina si un acusativo (expresado en el siguiente árbol como K, por 'caso') se manifiesta como $a$ atendiendo a reglas idiosincrásicas que tienen en cuenta tanto el tipo de verbo al que se asocia el complemento como las propiedades internas del propio complemento - animacidad, definitud, y ocasionalmente su forma específica, como en el caso de alguien, que debe estar marcado independientemente 
de su interpretación referencial-.

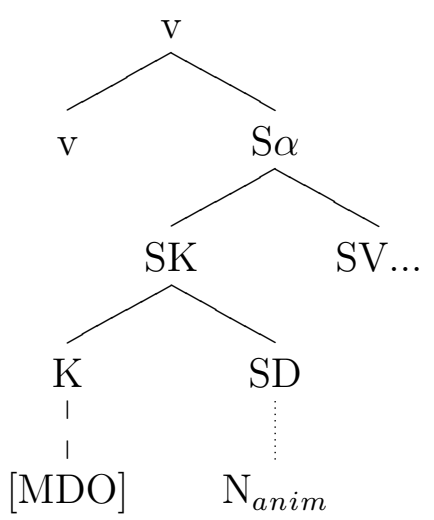

Esta regla de inserción de $a$ en el caso acusativo en el contexto donde el SN es animado podría formalizarse de la siguiente manera:

$$
\mathrm{K}_{\text {acusativo }} \longrightarrow a /\left[S K \mathrm{~K}\left[S_{D} \ldots \mathrm{N}_{\text {anim }} \cdots\right]\right]
$$

Este aspecto de la teoría de López no parece poder integrarse en el caso de los direccionales. La razón es que la regla de materialización que inserta $a$, crucialmente, tiene que hacer referencia al caso, que -sobre postulados de Morfología Distribuida- se realiza morfofonológicamente con un conjunto de reglas ciegas a la semántica, que toman en cuenta solo la posición sintáctica y propiedades morfológicas idiosincrásicas de las piezas léxicas involucradas en la construcción.

En cambio, en nuestro caso, donde los datos dicen que el efecto es muy semejante al que se da en los complementos directos, la proyección donde se da la alternancia no es de caso, sino un nudo preposicional con significado definido que está pedido semánticamente por la proyección que lo introduce, Dir -que exige una preposición de coincidencia terminal y rechaza una preposición estática como en-. Esto es un problema potencial para este aspecto de la propuesta de López, ya que no parece fácil, dentro de una teoría como la Morfología Distribuida, extender el poder de las reglas morfofonológicas de materialización hasta el punto de permitirles interferir con la selección semántica. ${ }^{9}$

La tercera propuesta que consideraremos es la de Rodríguez-Mondoñedo (2007). Para este autor, lo que define una construcción de MDO es que el constituyente que hace la función de complemento directo tiene propiedades formales que impiden que entre en concordancia con un verbo de la manera en que otros complementos directos lo pueden hacer. Simplificando algo las cosas, y sin entrar en detalles técnicos, Rodríguez Mondoñedo asume la teoría de que todo argumento debe recibir caso (Vergnaud, [1977] 2008; Chomsky, 1981) y de que el caso solo se obtiene de un núcleo cuando el argumento concuerda con él en todos sus rasgos (Chomsky, 2004). A partir de aquí, propone lo siguiente:

\footnotetext{
${ }^{9} \mathrm{Sin}$ embargo, es concebible que la propuesta pudiera ser adaptada con matices: por ejemplo, si con y $a$ se analizaran como preposiciones funcionales, tal y como ha propuesto Svenonius (2007), no sería inconcebible que la alternancia estuviera dictada por reglas idiosincrásicas de naturaleza morfofonológica. No obstante, la adaptación no es directa ni libre de problemas: una cuestión esencial, que el propio López nota (López, 2012, 59) es hasta qué punto se puede mantener la propuesta de que las reglas de inserción de $a$ solo hacen referencia a un contexto local. Por ejemplo, conforme a muchos autores, el SD cierra un ciclo sintáctico (Chomsky, 2001), lo cual produce el problema de cómo puede acceder K a la información contenida en $\mathrm{N}$, que está en otro ciclo distinto.
} 
1. En español, un complemento directo sin MDO es un complemento directo que ha recibido caso del verbo, ya que puede concordar completamente con él.

(90) Ernesto vio la casa.

2. el verbo español solo puede entrar en concordancia completa con un complemento directo que tenga número, pero nunca persona (Rodríguez-Mondoñedo, 2007, 167).

*Ernesto vio mí.

3. Consecuentemente, si algo que empieza como complemento directo tiene persona, no puede concordar con el verbo. Esto hace que no pueda recibir caso del verbo, y que, para legitimar su caso, deba entrar en concordancia con otra proyección distinta.

En el caso concreto del complemento directo, la proyección que asigna caso a un SD que contenga un rasgo de persona es una que contiene rasgos de dativo, y de ahí que la materialización del MDO en español -y otras muchas lenguas- sea un marcado dativo. El complemento directo se puede desplazar a esa proyección, por lo que al igual que en la teoría de Torrego o López, hay movimiento, pero nótese que aquí el movimiento crucialmente es un resultado de la necesidad de legitimar un rasgo de persona. Torrego y López tratan la animacidad como un epifenómeno que se sigue de la posición que ocupa un complemento directo con $a$ dentro de la estructura, mientras que Rodríguez Mondoñedo la trata como un rasgo propio del constituyente antes de desplazarse, que en último término desencadena la serie de operaciones que terminan produciendo MDO. Esta teoría es, en principio, más atractiva para explicar el MDO con los direccionales, porque en ese caso no hay evidencia de movimiento, pero sí de que las propiedades internas del SD son distintas.

La propuesta de Rodríguez Mondoñedo, específicamente, es que la animacidad está asociada a un rasgo [persona], que se origina en el sustantivo y que, bajo ciertas condiciones, puede copiarse en el SD -lo cual tiene efectos sobre la definitud y especificidad(Rodríguez-Mondoñedo, 2007, 191 y sigs.). Los complementos directos sin determinante explícito (niños, por ejemplo) no pueden llevar a porque en ellos el rasgo de persona no se copia en un nudo más alto, por lo que no tiene que entrar en concordancia con el verbo. Los pronombres alguien, nadie y quién, que se asocian a la presencia de a, pese a las apariencias contienen un determinante fuerte (materializado como -ien) con valor de persona, por lo que generalmente el verbo no es suficiente para asignarles caso por sí mismo.

Hay varios aspectos de esta teoría que nos interesan para el análisis del marcado diferencial con los direccionales. La primera es que la causa del marcado es puramente sintáctica, en asociación con un rasgo de [persona] que define correctamente la clase de los nombres y pronombres animados como la que lleva con en la estructura direccional. La segunda es que la razón última es la necesidad de recibir caso a través de la concordancia, que debe ser completa y por tanto incluir un rasgo de persona. Esto se debe a que el español tiene una propiedad significativa que diferencia a con entre todas las preposiciones:
a. conmigo
b. contigo
c. consigo 
La preposición con, con pronombres de persona -que obviamente son los candidatos más claros a tener un rasgo [persona]- muestra una morfología especial que ninguna otra preposición posee: -igo, junto a un segmento - $m$-, - $t$ - o - $s$ - que representa las distinciones entre primera, segunda y tercera (reflexiva). Tomamos esto como prueba de que con es la única preposición que puede entrar en concordancia legitimar por sí misma con un rasgo de persona, y que por tanto es compatible con un sintagma nominal que lleve este rasgo formal. Vayamos paso a paso.

La estructura verbal de ir y el resto de verbos de su clase, con un SDir, selecciona una preposición de coincidencia terminal. Para la interpretación direccional relevante, el español puede elegir entre con y $a$. Sin embargo, con puede legitimar un rasgo de persona, y a no entra en concordancia con este rasgo.

$$
\begin{aligned}
& \text { a. a ti } \\
& \text { b. } * \text { atigo }
\end{aligned}
$$

Si el complemento del direccional es un pronombre de primera persona $u$ otro elemento animado, $a$ es incapaz de concordar con él en persona. La consecuencia automática es que la preposición no puede asignarle caso por sí sola; el verbo, sin embargo, tampoco puede, porque es transitivo, de manera que la estructura es agramatical.

(94) *Fue a ti.

Si introducimos con, en cambio, la preposición puede concordar también en persona, y legitima así ese rasgo, asignando caso.

Fue contigo.

A la inversa, si el sustantivo no tiene un rasgo de persona, introducir la preposición con direccional dará una estructura agramatical, porque la preposición tiene que cotejar un rasgo de [persona] que el complemento no tiene. Por eso, si nos concentramos en la lectura direccionmal, (96) es agramatical.

*Fue con la mesa.

\subsection{Direccionales con con en una perspectiva comparada}

Estamos ahora en situación de explicar por qué la construcción direccional con con está restringida a través de las lenguas del mundo.

La primera restricción que explica esto es el marcado diferencial de objeto. Si una lengua tiene marcado diferencial de objeto, siguiendo la lógica de la teoría de Rodríguez Mondoñedo, es porque tiene gramaticalizado un rasgo [persona] que se encuentra sintácticamente activo. Esto tiene efectos en la forma en que se asigna caso a los complementos directo, de manera que si la lengua no distingue dos tipos de complementos directos por su animacidad, esperamos que el rasgo de [persona] no sea sintácticamente activo en esa lengua. Esto quiere decir que si la lengua no tiene marcado diferencial en el complemento directo, tampoco esperamos que lo tenga en la lectura direccional, porque en ambos casos la diferencia surge de la presencia de [persona], y o lo tienen los dos casos, o ninguno.

De la misma manera, otra posible causa de variación que descarte de entrada a algunas lenguas es si en su estructura sintáctica la preposición que habitualmente se emplea como 
comitativa expresa una relación terminal o central; cabe la posibilidad de que en algunas lenguas -como el inglés, véase Rapoport (to appear)- la preposición comitativa sea de coincidencia central. Esto, por sí solo, eliminaría la lectura direccional en tanto que Dir descarta esta clase de preposiciones como sus complementos.

La situación más compleja se produce en las lenguas donde hay -al menos en algunas variedades y casos- fenómenos de Marcado Diferencial de Objeto: el francés, el catalán y el italiano son lenguas en las que hay al menos una parte de MDO, y solo la primera lengua admite las construcciones direccionales con con. En italiano, donde no se admite la lectura direccional, hay variedades en el Sur en las que sí hay MDO (97) (Iemmolo, 2013), y en catalán, donde se admite con los pronombres (98) (Todolí, 2008) también se rechaza la lectura.

(97) A te, non ti sopporto più.

A ti, no te soporto más

'A ti, ya no te soporto'

(98) Tothom et mirava a tu.

todos te miraban a ti

'Todo el mundo te miraba a ti'

¿Por qué no se da, pues, la construcción en catalán o en italiano? La razón, creemos, está en que la naturaleza de la preposición equivalente a con y si el sistema pronominal tiene o no tiene sensibilidad a la animacidad en esta lengua.

Conforme a este criterio, hay que diferenciar el francés y el italiano, por un lado, del catalán. Aunque en ninguna de estas lenguas se observa que la preposición equivalente a con se flexione con respecto a la persona, en francés la pronominalización de un complemento preposicional puede depender de la animacidad. Esto se observa en el contraste entre los ejemplos siguientes, del francés: esto muestra que en esta lengua el sistema preposicional mantiene una distinción de animacidad.
a. Je pense souvent à Marie.
yo pienso a-menudo a Marie
'Pienso a menudo en María'
b. Je pense souvent à elle.
yo pienso a-menudo a ella
'Pienso en ella a menudo'
a. Je pense souvent à quitter le pays. yo pienso a-menudo a abandonar el país
'Pienso a menudo en irme del país'
b. J'y pense souvent.
yo-en-eso pienso a-menudo
'Pienso en eso a menudo'

En catalán esto no sucede; la distinción entre clíticos preposicionales (en o hi) no se guía por la animacidad del complemento, sino por el tipo de preposición empleada (Todolí, 2008, 1402):
a. No sé res d'aquesta persona.
No sé nada de-esta persona 
'No sé nada de esta persona'

b. No en sé res.

No de-ella sé nada

'No sé nada de ella'

(102) a. Pere es casa amb Marta demà.

Pere se casa con Marta mañana

'Pere se casa con Marta mañana'

b. Pere s'hi casa demà.

Pere se-en-ella casa mañana

'Pere se casa con ella mañana'

Esta ausencia de sensibilidad a la animacidad en el sistema preposicional elimina al catalán de entre las lenguas en las que esperamos que haya alternancias de direccionalidad basadas en [persona].

El lector ya habrá notado que algo más hay que decir del italiano, porque en esta lengua hay alternancias preposicionales basadas en la animacidad, al igual que en francés.
a. Penso spesso a la Loren.
pienso a-menudo en la Loren
'Pienso a menudo en Sofía Loren'
b. Penso spesso a lei.
pienso a-menudo a ella
'Pienso a menudo en ella'

(104) a. Penso spesso alla politica.

pienso a-menudo en-la política

'Pienso a menudo en la política'

b. Ci penso spesso.

En-ella pienso a-menudo

'Pienso en eso a menudo'.

¿Qué es lo que sucede en italiano, pues, para que no se produzcan direccionales con con? Es cierto que esta ausencia no está prevista con claridad en nuestro análisis, y con completa seguridad exige un estudio comparativo más detallado del italiano frente al español. Sin embargo, quizá sea posible ofrecer alguna especulación acerca de por qué el italiano es una excepción.

Una propiedad que tiene la preposición con en italiano, y que ni el francés avec ni el español con tienen es que la preposición está afectada por el género y número del complemento cuando este es definido. Este rasgo es más del italiano coloquial que del formal.
a. con un coltello
con un cuchillo
'con un cuchillo'
b. col coltello
con-MASC.SG cuchillo
'con el cuchillo'




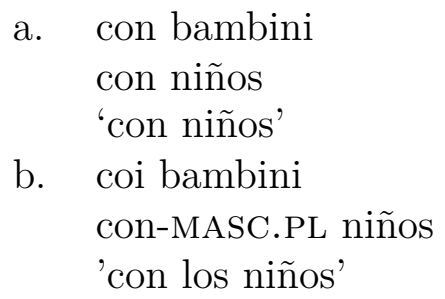

Estas formas -que aparecen solo en contextos donde el complemento es definido, y por lo tanto tienen un determinante fuerte- reciben en gramática italiana, a veces, el nombre de 'artículos preposicionales'. Aunque el análisis más tradicional es de corte morfofonológico -la preposición y el artículo se funden por su carácter fonológicamente defectivo-, la explicación deja fuera, obviamente, el problema de que un es igualmente defectivo y no produce la fusión. Una alternativa para analizar estos casos sería proponer que en italiano las preposiciones tienen que concordar en género y número con el determinante, y que esta concordancia bloquea la posible concordancia en persona. Si esta teoría puede mantenerse, lo que sucedería en el caso del italiano es que con sería insuficiente para satisfacer un rasgo de persona en un direccional, por lo que no surge la alternancia.

\section{Conclusiones}

En este trabajo hemos examinado las interpretaciones direccionales a las que dan lugar los sintagmas introducidos por con en español, y hemos concluido que solo pueden aparecer con aquellos verbos que denotan una dirección, pero no una meta. En español, con es una preposición de coincidencia terminal, por lo que está habilitada para aparecer como complemento de un núcleo direccional que implica necesariamente un desplazamiento a lo largo de la dimensión espacial.

Seguidamente, hemos mostrado que el fenómeno tiene relación con el marcado diferencial de objeto que se observa en español, de manera estándar, en el caso del complemento directo. De entre las teorías que han analizado este fenómeno, hemos concluido que la que más fácilmente puede extenderse al caso de los direccionales es la de Rodríguez Modoñedo, donde lo especial de los objetos con marcado diferencial es que poseen un rasgo [persona] que les fuerza a establecer relaciones con categorías no verbales para satisfacer su concordancia. Una consecuencia que se sigue de esto es que, si el movimiento es realmente un factor que acompaña al marcado diferencial en el caso tradicional, debe ser una propiedad específica de los complementos directos, o tal vez de los constituyentes argumentales de naturaleza nominal, ya que cuando el marcado diferencial afecta a complementos introducidos por preposición no se ven diferencias posicionales entre ellos.

Nuestro trabajo tiene consecuencias potenciales también en otras áreas, y no nos ha sido posible desarrollarlas en los límites relativamente reducidos de un artículo de investigación. La primera de ellas es la naturaleza del rasgo de [persona] y la pregunta de en qué posición dentro de la estructura del sintagma determinante aparece. En la teoría de Rodríguez-Mondoñedo (2007) se trata de un rasgo presente en Sn -una proyección funcional entre el determinante y el sustantivo léxico- que puede conservarse activa en el nivel de SD. Una pregunta obvia es si se da alguna clase de copia de persona entre D y n o es más bien que la definición del rasgo de persona es fruto de una categoría funcional más alta que n y perteneciente al dominio del determinante. Si fuera así, tal vez 
los sintagmas escuetos se comportan como no animados porque carecen de esa proyección, y los sustantivos que alternan entre dos lecturas lo harían en función de la presencia o ausencia de estas proyecciones. No tenemos nada que decir sobre este problema, aunque es necesario apuntarlo.

Otra pregunta que queda abierta se refiere a la naturaleza del sistema preposicional, y concretamente a qué sucede con los sustantivos animados cuando están introducidos por preposiciones distintas de con en diversos usos. La cuestión que surge aquí es de qué manera se legitima su rasgo de persona, necesario para la asignación de caso. Una primera posibilidad es que sean solo las proyecciones verbales bajas las que sean incapaces de legitimar, en español, persona por sí mismas, por lo que cuando falla la preposición el sustantivo no puede recibir caso de otro elemento. Sin embargo, otras proyecciones más altas podrían legitimar ese caso, ya que concordarían en persona. Otra posibilidad sería que en contextos no direccionales, donde la preposición no está seleccionada por Dir, la estructura preposicional pueda ser más compleja e incluir proyecciones fuincionales que permitan legitimar la persona a las que, léxicamente, no tienen esta capacidad. Sería, por ejemplo, una proyección preposicional funcional p pequeña, como propone Svenonius (2010).

$$
\left[{ }_{S p} \mathrm{p}\left[{ }_{S P} \mathrm{P}[\mathrm{SD} \ldots]\right]\right]
$$

Si Dir tiene que seleccionar una propiedad léxica, esto impediría que Sp pudiera intervenir entre P y Dir, restringiendo el tipo de preposición que pueda aparecer en ese contexto a las que, sin ayuda de p, pueden legitimar [persona]. Otras preposiciones, como hasta o desde, que pueden funcionar como complemento de Dir introduciendo argumentos personales, poseerían también la capacidad de legitimar [persona] por ellas mismas, aunque aportan significados distintos con matices propios (Romeu, 2013). A favor de la propuesta de que las preposiciones pueden tener que combinarse con material adicional para legitimar el rasgo de persona tenemos el contraste de (108).

$$
\begin{aligned}
& \text { a. } \operatorname{tras}(* \text { de) la mesa } \\
& \text { b. } \operatorname{tras} *(\text { de }) \text { mí }
\end{aligned}
$$

Con tras, un pronombre personal solo está legitimado si se añade de, que, en cambio, no se siente como normal si el complemento es un nombre común. Esto sería coherente con una situación en la que tras por sí sola no legitima [persona], pero una capa estructural adicional, a la que tras se incorpora después, tiene ese poder.

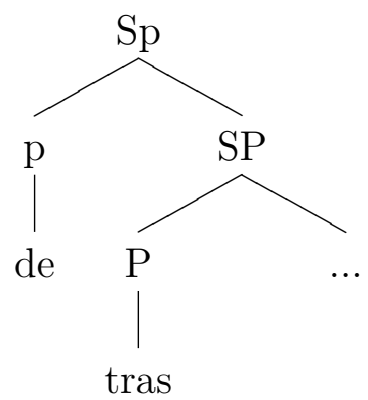

Quedan, pues, cabos sueltos, pero esperamos que al menos hayamos sido capaces de arrojar algo de luz sobre una construcción que no estaba lo suficientemente analizada en español 
y sus potenciales consecuencias para el marcado diferencial de objeto.

\section{Referencias}

Arche, María Jesús. 2006. Individuals in time: Tense, aspect and the individual - stage distinction. Amsterdam/Philadelphia: John Benjamins Publishing Company.

Bossong, Georg. 1985. Differentielle Objektmarkierung in den Neuiranischen Sprachen. Tübingen: Gunter Narr Verlag.

Brauns, Julius. 1909. Über den präpositionalen Accusativ im Spanischen mit gelegentlich Berücksichtigung anderer Sprachen. Hamburg.

Brucart, José María. 2010. La alternancia ser y estar y las construcciones atributivas de localización. En A. Avellana (ed.), Actas del V Encuentro de Gramática Generativa, 115-152. Neuquén: Editorial Universitaria del Comahue.

Brucart, José María. 2012. Copular alternations in Spanish and Catalan attributive sentences. Linguística: Revista de Estudos Linguísticos da Universidade do Porto 7. 9-43.

Caha, Pavel. 2009. The nanosyntax of case: University of Troms $\varnothing$ dissertation.

Chomsky, Noam. 1981. Lectures on government and binding. Dordrecht: Foris.

Chomsky, Noam. 2001. Derivation by phase. En Michael Kenstowicz (ed.), Ken Hale: A life in language, 1-52. Cambridge, Ma.: MIT Press.

Chomsky, Noam. 2004. Beyond explanatory adequacy. En Adriana Belletti (ed.), Structures and beyond: The cartography of syntactic structures, vol. 3, 104-131. New York: Oxford University Press.

Company, Concepción. 2002. El avance diacrónico de la marcación preposicional en objetos directos animados. En J. C. Torres et al. (ed.), Actas del ii csel. presente y futuro de la lingüistica, 146-154. Madrid: CSIC.

De Bruyne, Jacques. 1999. Las preposiciones. En Ignacio Bosque y Violeta Demonte (eds.), Gramática descriptiva de la lengua española, vol. 1, 657-704. Madrid: Espasa Calpe.

De Cuyper, Gretel. 2004. La estructura léxica de la resultatividad y su expresión en las lenguas germánicas y románicas. Antwerpen: Universiteit Antwerpen Ph. D. dissertation.

De Miguel, Elena. 1992. El aspecto en la sintaxis del español: perfectividad e impersonalidad. Madrid: Ediciones de la Universidad Autónoma de Madrid.

De Miguel, Elena y Marina Fernández-Lagunilla. 2000. El operador aspectual se. Revista española de lingüistica 30(1). 13-43.

Delbecque, Nicole. 1998. Why Spanish has two transitive construciton frames. Leuvense Bijdragen 87. 387-415. 
Delbecque, Nicole. 1999. Two transitive construction frames in Spanish: the prepositional and the non-prepositional accusative. En L. De Stadler y C. Eyrich (eds.), Issues in cognitive linguistics, 407-424. Berlin: De Gruyter.

Delbecque, Nicole. 2002. A construction grammar approach to transitivity in Spanish. En K. Davidse y B. Lamiroy (eds.), The nominative and accusative and their counterparts, 81-130. Amsterdam: John Benjamins.

Diez, Friedrich. 1844. Grammatik der romanischen Sprache. Bonn: E. Webber.

Enghels, Renate. 2013. Transitivity of Spanish perception verbs: a gradual category. Borealis. An International Journal of Hispanic Linguistics 2(1). 35-56.

Fábregas, Antonio. 2007. An exhaustive lexicalization account of directional complements. En Monika Bašić, Marina Pantcheva, Minjeong Son y Peter Svenonius (eds.), Tromsø working papers on language and linguistics: Nordlyd 34.2, Special issue on Space, Motion, and Result, 165-199. Tromsø: University of Tromsø. Available at http://www.ub.uit.no/baser/nordlyd/.

Hale, Ken. 1986. Notes on world view and semantic categories: some Warlpiri examples. En Pieter Muysken y Henk van Riemsdijk (eds.), Features and projections, 233-254. Dordrecht: Foris.

Hale, Ken y Samuel Jay Keyser. 2002. Prolegomenon to a theory of argument structure (Linguistic Inquiry Monographs 39). Cambridge, Ma.: MIT Press.

Halle, Morris y Alec Marantz. 1993. Distributed Morphology and the pieces of inflection. En Kenneth Hale y Samuel Jay Keyser (eds.), The view from building 20: Essays in linguistics in honor of Sylvain Bromberger, 111-176. Cambridge, Ma.: MIT Press.

Harley, Heidi. 1995. Subjects, events, and licensing. Cambridge, Ma.: MIT dissertation.

Hills, E. C. 1920. The accusative a. Hispania 3. 216-222.

Iemmolo, Giorgio. 2013. Topicality and differential object marking: evidence from Romance and beyond. University of Zurich.

Joly, André. 1971. La complément verbal et le morphème $a$ en béarnais. observations sur le genre et la fonction dans les langues romanes. Zeitschrift für romanische Philologie 87. $286-305$.

Leonetti, Manuel. 2004. Specificity and differential object marking in Spanish. Catalan Journal of Linguistics 3. 75-114.

López, Luis. 2012. Indefinite objects: scrambling, choice functions and differential marking, vol. 63 Linguistic Inquiry Monographs. Cambridge, Mass.: MIT Press.

Marantz, Alec. 1991. Case and licensing. En Proceedings of the Eastern States Conference on Linguistics, vol. 8, 234-253. MIT.

Mateu, Jaume. 2002. Argument structure: Relational construal at the syntax interface. Barcelona: Universitat Autónoma de Barcelona dissertation. 
Morimoto, Yuko. 2001. Los verbos de movimiento. Madrid: Visor.

Neeleman, Ad y Kriszta Szendrői. 2007. Radical pro-drop and the morphology of pronouns. Linguistic Inquiry 38(4). 671-714.

Pottier, Bernard. 1968. L'emploi de la préposition a devant l'object en espagnol. Bulletin de la Societé de Linguistique 1. 83-95.

Ramchand, Gillian. 2008. Verb meaning and the lexicon. Cambridge University Press.

Rapoport, Tova. to appear. Central coincidence: the preposition with. En Jean-Marie Merle y Agnès Steuckardt (eds.), Prépositions et aspectualité, Paris: Ophrys.

Real Academia Española y Asociación de Academias de la Lengua Española. 2009. Nueva gramática de la lengua española. Madrid: Espasa Calpe.

Rodríguez-Mondoñedo, Miguel. 2007. The syntax of objects: agree and differential object marking. Storrs: University of Connecticut Ph. D. dissertation.

Romeu, Juan. 2013. Locations and paths: the structure of prepositions in a minimal cartography. Madrid: CSIC Ph. D. dissertation.

Starke, Michal. 2009. Nanosyntax: A short primer to a new approach to language. En Peter Svenonius, Gillian Ramchand, Michal Starke y Knut Tarald Taraldsen (eds.), Tromsø working papers on language and linguistics: Nordlyd 36.1, Special issue on Nanosyntax, 1-6. Troms $\varnothing$ : University of Troms $\varnothing$. Available at http://www.ub.uit.no/baser/nordlyd/.

Svenonius, Peter. 2007. Adpositions, particles, and the arguments they introduce. En Eric Reuland, Tanmoy Bhattacharya y Giorgos Spathas (eds.), Argument structure, 71-110. Amsterdam: John Benjamins.

Svenonius, Peter. 2010. Spatial prepositions in English. En Guglielmo Cinque y Luigi Rizzi (eds.), Mapping spatial PPs: Cartography of syntactic structures, vol. 6, 127-160. Oxford: Oxford University Press. Prepublication draft available at http://ling.auf.net/lingBuzz/000001.

Talmy, Leonard. 1983. How language structures space. En H. Pick y L. Acredolo (eds.), Spatial orientation: Theory, research, and application, 225-282. New York: Plenum.

Talmy, Leonard. 1985. Lexicalization patterns: Semantic structure in lexical forms. En Timothy Shopen (ed.), Language typology and syntactic description, iii: Grammatical categories and the lexicon, 57-149. Cambridge: Cambridge University Press.

Talmy, Leonard. 1991. Path to realization: A typology of event conflation. En Proceedings of the seventeenth annual meeting of the berkeley linguistics society, 480-519. Berkeley, Ca.: Berkeley Linguistics Society.

Todolí, Julia. 2008. Els pronoms. En Joan Mascaró Joan Solá, Maria-Rosa Lloret y Manuel Pérez Saldanya (eds.), Gramàtica del catalá contemporani, vol. 2, cap. 6, 13371433. Barcelona: Empúries edició definitiva edn. 
Torrego, Esther. 1998. The dependencies of objects Linguistic Inquiry Monographs 34. Cambridge, Ma.: MIT Press.

Vergnaud, Jean-Roger. [1977] 2008. Letter to Noam Chomsky and Howard Lasnik on "Filters and control". En Robert Freidin, Carlos P. Otero y Maria Luisa Zubizarreta (eds.), Foundational issues in linguistic theory: Essays in honor of Jean-Roger Vergnaud, 3-15. Cambridge, Ma.: MIT Press.

Von Heusinger, Karl y Georg A. Kaiser. 2011. Affectedness and differential object marking in Spanish. Morphology 21(1). 593-617.

Weerman, Fred y Jacqueline Evers-Vermeul. 2002. Pronouns and case. Lingua 112. 301338. 